\title{
El método de cooperación interpretativa como estrategia lectora'
}

\author{
The Interpretive Cooperation Method as a Reading Strategy
}

\author{
AURORA MARTÍNEZ EZQUERRO \\ Universidad de La Rioja \\ España \\ aurora.martinez@unirioja.es
}

(Recibido: 23-I2-20I5; aceptado: 03-O2-20I6)

Resumen. El "Método de cooperación interpretativa" tiene como finalidad que el lector desarrolle de forma compartida el conocimiento de la lectura abordada mediante la intervención en espacios de práctica colaborativa en los que el mediador estimula la reflexión conjunta. Esta técnica desarrolla la competencia interpretativa, esto es, la capacidad de comprender y reconstruir el sentido de una obra entendida como un tejido complejo de significación; asimismo, desarrolla los contenidos que corresponden a elementos vertebradores del currículum de Educación Secundaria, como son las destrezas comunicativas orales y escritas, el conocimiento de la lengua $y$, de forma especial, la competencia en educación literaria.

La necesidad de capacitar a los alumnos en el ámbito lector constituye el objetivo capital de la presente propuesta y permite practicar las destrezas orales de forma adecuada en un ámbito de interrelación y retroalimentación utilizando adecuadamente la lengua como instrumento para la actividad de "re-creación" literaria.

Palabras clave: educación literaria; estrategias lectoras; competencia interpretativa; currículo.
Abstract. The "Interpretive Cooperation Method" has as ground purpose that the reader develops in a shared way the knowledge of the approached text. It is performed by means of the intervention through spaces of collaborative practice in which the mediator stimulates the joint reflection. This technique develops the interpretative competence, that is, the ability to understand and reconstruct the sense of a reading understood as a complex web of meaning. It also develops the contents that correspond to the unifying elements from the Secondary Education curriculum, such as the oral and written communication skills, the knowledge of the language and, particularly, literary education's competence.

The need to train pupils in the reading area constitutes the main aim of the present offer, since it allows them to practise the oral skills properly, in an area of interaction and feedback. It is carried out it by using the language adequately as an instrument for the literary "re-creation" activity.

Keywords: literary education; reading strategies; interpretative competence; curriculum.

\footnotetext{
I Para citar este artículo: Martínez Ezquerro, Aurora (20I6). El método de cooperación interpretativa como estrategia lectora. Alabe 14. [www.revistaalabe.com]

DOI: IO.I5645/Alabe2OI6.I4.I
} 
[...] un texto se distingue de otros tipos de expresiones por su mayor complejidad. El motivo principal de esa complejidad es precisamente el hecho de que está plagado de elementos no dichos [...].

Umberto Eco, Lector in fábula, pág. 73.

\section{Introducción}

Mucho se ha reflexionado y abundantes páginas se han escrito sobre la importancia de fomentar los hábitos de lectura en los alumnos junto con el papel que desempeña el docente en estas funciones (Martos y Rösing, 2009). En relación con el profesor como mediador didáctico de este proceso, comparto las afirmaciones de Mendoza Fillola (2008: 2), quien indica que

Las funciones del profesor de literatura -mediador. formador. crítico. animador. motivador y dinamizador- dependen y se establecen en relación con la misma concepción que el profesor tenga sobre el hecho literario, su valoración formativa de las aportaciones de las distintas tendencias/perspectivas teóricas y, en especial, de los fines que se propone como objeto de su actividad respecto al tipo de formación que considera como más pertinente para sus alumnos. Todo ello está en función de las opciones metodológicas que adopta.

Es obvio que el papel desempeñado por el profesor en este proceso es primordial, su interés e iniciativa en el desarrollo lector conseguirán los objetivos propuestos. Suscribimos las palabras de López y Encabo (2013: I75) quienes también ponen de relieve la iniciativa del docente en esta aventura hacia el desarrollo de la educación lectora; es más, en relación con el placer de la lectura inciden en la importancia que tiene la creatividad de los formadores, que procuran espacios e iniciativas que resulten atractivas para los lectores y les devuelvan la ilusión por leer.

En el presente trabajo vamos a plantear, entre otras cuestiones, un método que se halla en consonancia con este planteamiento de interacción comunicativa de interpretación literaria y que también recoge los presupuestos de atención a la diversidad del alumnado. Partimos de que en este contexto el docente es parte fundamental del triángulo "mediador-lector-obra/autor" (permítasenos, en este caso, la licencia de incluir el binomio creación/creador). Que los alumnos sientan interés por la lectura es, no obstante, una asignatura que no vamos a denominar pendiente pero sí preocupante por cuanto constituye uno de los objetivos prioritarios de cualquier docente de niveles no universitarios -grado educativo que nos compete- interesado en fomentar la competencia lectora, 
lato sensu. No obstante, debemos tener presente en estos intentos adoctrinadores que la competencia básica "aprender a aprender" se encuentra en relación directa con el trabajo que aquí nos ocupa y reconocemos que es, muchas veces, difícilmente aprehensible puesto que posee un gran componente "volitivo" que puede interferir negativamente en el desarrollo de cualquier proceso de aprendizaje (Martínez, 2OII: 74). Recordemos lo que indica el currículo de Educación Secundaria Obligatoria recogido en la $\mathrm{LOE}^{2}$ en relación con la mencionada competencia básica:

Aprender a aprender supone disponer de habilidades para iniciarse en el aprendizaje y ser capaz de continuar aprendiendo de manera cada vez más eficaz y autónoma de acuerdo a los propios objetivos [...]. Esta competencia tiene dos dimensiones [...]. Por un lado, la adquisición de la conciencia de las propias capacidades (intelectuales, emocionales, físicas) [...] y las estrategias necesarias para desarrollarlas [...]. Por otro lado, disponer de un sentimiento de competencia personal, que redunda en la motivación, la confianza en uno mismo y el gusto por aprender [...].

Asimismo en el currículo de Educación Secundaria perteneciente a la LOMCE3, se recoge lo siguiente en relación con esta "competencia clave":

La competencia de aprender a aprender se promueve mediante el ejercicio de los procesos cognitivos que se realizan en el desarrollo del currículo básico, tales como analizar, sintetizar, relacionar, comparar, aplicar, evaluar, argumentar, etc. y favoreciendo en los alumnos y alumnas el gusto y la satisfacción que produce el descubrimiento de la verdad.

Nos encontramos, por ende, con uno de los “escollos” consustanciales a la práctica docente; se trata de una actitud y capacidad que no siempre se consigue desarrollar pues hay diversos elementos que en ella inciden y que rebasan lo meramente académico -en sentido amplio, pues la dimensión psico-afectiva es fundamental en estos niveles-. Pero centrémonos en lo que nos ocupa. Nos proponemos contribuir al desarrollo de las competencias que fomentan la educación literaria y, concretamente, la competencia lectora que implica, asimismo, la consiguiente capacidad de reflexión e interpretación. Las palabras de la profesora Campos corroboran esta postura: "Lo que en última instancia considero que es indisociable con nuestra labor didáctica es conseguir personas que reflexionen sobre lo que tienen ante sus ojos, rompiendo con la pasividad de ser meros receptores" (2004: 48). Por otro lado, la labor del mediador es imprescindible, una de sus

\footnotetext{
${ }^{2}$ ORDEN ECI/222O/2007, de I2 de julio, por la que se establece el currículo y se regula la ordenación de la Educación Secundaria Obligatoria (BOE, 2 I de julio de 2007), págs. 3І69I-3I692.

${ }^{3}$ Real Decreto IIо5/20I4, de 26 de diciembre, por el que se establece el currículo básico de la Educación Secundaria Obligatoria y del Bachillerato (BOE, 3 de enero de 2OI5), pág. 535 .
} 
funciones es "reconocer el libro adecuado para sus potenciales lectores, pero siempre teniendo en cuenta la palabra del lector" (Quiles, Palmer y Rosal, 20I5: 89).

Diversos métodos ofrecidos por expertos en el tema contribuyen a la consecución de estos objetivos, que no es tarea baladí. El propósito del docente es “despertar", inicialmente, el placer por la lectura. Hay numerosas formas de acercarse a la misma, que son sobradamente conocidas por los que a estos menesteres nos dedicamos. Muchos años en las aulas de Educación Secundaria junto con la reflexión y formación adecuadas permiten ir buscando, experimentando o seleccionando ciertos métodos que tratan de despertar a la "princesa" dormida. Nos centraremos en uno de los que ofrece la posibilidad de "amalgamar" diversas técnicas que fomentan las competencias mencionadas, las habilidades comunicativas orales y escritas, el conocimiento de la lengua, la capacidad de reflexión e interpretación, y la educación literaria, sin olvidar la atención a la competencia básica "aprender a aprender".

\section{Aspectos metodológicos}

Partimos de tres aspectos fundamentales en los que se basa el "Método de cooperación interpretativa” para alumnos de Educación Secundaria (y que ha sido también puesto en práctica con gran éxito por los alumnos del Máster de Profesorado de la especialidad de Lengua Castellana y Literatura en el período de prácticas que habitualmente desarrollan en los centros educativos): en primer lugar, el contexto docente es interactivo y en él se construye el conocimiento mediante el uso de la palabra, concretamente, la reflexión literaria constituye una actividad que se enriquece en espacios de colaboración (dinámica de grupos); por otro lado, el lector descodifica el texto y paralelamente lo completa a la luz de sus conocimientos y experiencias compartidas (cooperación interpretativa que se adscribe a la teoría de la recepción); y finalmente, este intercambio se desarrolla en el espacio docente, esto es, a la luz del currículum que establece unos objetivos explicitados como capacidades y competencias (integración curricular). Se crean, de esta forma, unas posibilidades metodológicas absolutamente enriquecedoras, es más, se fomenta la comunicación; así, en palabras de López y Jerez, "La variedad de actividades, espacios y tiempos que es demandada favorece además la comunicación, la cooperación y el descubrimiento de la imaginación en la propia vida” (20IO: 7). De esta forma, el acto de la lectura supone una interacción entre lector y autor/obra, y se integran lectura, expresión escrita y oral, y las destrezas consiguientes. Veamos la triple dimensión del método propuesto.

\section{I. Dinámica de grupos}

El contexto docente es interactivo y en él se desarrollan "permanentemente una serie de transacciones y negociaciones que determinan las actividades" (Oliva, I996: I34I35). No podemos olvidar que "en cierto sentido, la enseñanza es conversación; de ahí 
que cualquier situación de uso de la palabra sea un microcosmos de relaciones sociales y personales" (Stubbs, 1984: I3). Las actividades y estrategias de interacción son fundamentales porque en ellas el usuario de la lengua actúa de forma alterna como hablante y oyente para construir, conjuntamente, una conversación mediante la negociación de significados siguiendo el principio de cooperación. Concretamente, la competencia pragmática (Marco Común Europeo, 2OOI: I2O) se refiere al conocimiento que posee el usuario de los principios según los cuales los mensajes se organizan, estructuran y ordenan (competencia discursiva), se utilizan para realizar funciones comunicativas (competencia funcional) y se secuencian siguiendo esquemas de interacción y de transacción (competencia organizativa).

El profesor es la figura clave en el proceso de enseñanza, puede ser transmisor, orientador, animador..., y según este, el alumno optará por un papel u otro. Así en el proceso didáctico de la dinámica de grupos, el discente es, por un lado, emisor de los actos comunicativos y crea situaciones que permiten el conocimiento interpersonal y, por otro, es receptor que se retroalimenta del pacto comunicativo.

La importancia de las técnicas didácticas que fomentan este principio es un factor decisivo para lograr un aprendizaje significativo (Gómez de Benito, 200I). Se trata de un modelo centrado en el alumno -considerado como sujeto de la educación- y en el que el profesor estimula la reflexión en un ambiente de confianza que contribuye al cambio positivo de participación activa a la vez que se genera conocimiento. Las dinámicas de grupo constituyen unas productivas estrategias que emplea un coordinador para estructurar, fomentar, motivar o estimular a sus miembros en el proyecto o trabajo que les reúne. En este sentido, Cassany (2002: I63) juzga importante la aportación más global que ha hecho la psicología humanista a la didáctica de la lengua al dar una dimensión más social y personal a la clase; considera que "Aprender lengua no es únicamente ejercitar habilidades o adquirir contenidos, sino también proyectar la propia personalidad en un medio de expresión”. Las clases se tornan espacios de relación interpersonal y, desde esta perspectiva, la expresión oral se aborda de forma activa para que los alumnos se sientan cómodos en el aula y enriquezcan el acto comunicativo mediante la expresión de aspectos que potencian los vínculos afectivos.

\subsection{Cooperación interpretativa}

El profesor Mendoza Fillola (2008: 3) valora la importancia que ofrece el trabajo de participación efectiva en el proceso de recepción de una obra y considera que es precisa la actualización interpretativa del discurso literario, si bien es necesario tener en cuenta tres aspectos:

a) la literatura es un conjunto de producciones artísticas que se definen por convencionalismos estético-culturales y que, en ocasiones, es un reflejo del devenir del grupo cultural;

b) las producciones literarias también se definen por la presencia acumulada de deter- 
minados (aunque no siempre exclusivos ni específicos) usos y recursos de expresión propios del sistema lingüístico y por su organización según estructuras de géneros; y

c) el proceso de percepción del significado de un texto literario no es una actividad espontánea, ni el significado es el resultado automático de una lectura de cariz denotativo.

La semiótica de la recepción se halla implícita en este enfoque interpretativo. Según Umberto Eco, un texto, tal como aparece en su superficie (o manifestación) lingüística, representa una cadena de artificios expresivos que el destinatario debe actualizar (2003: 73). Podemos entender que los "espacios en blanco o intersticios que hay que rellenar", en palabras del semiólogo, permiten que mediante el método propuesto los destinatarios, esto es, los alumnos lectores, añadan la plusvalía de sentidos (es lo que considera Eco "función didáctica"), sin olvidar la "función estética”, es decir, la violación de las reglas normales de conversación. Se nos ofrece la posibilidad, por tanto, de completar el paso de una función a otra, cuando un texto permite dejar al lector la iniciativa interpretativa (si bien normalmente desea ser interpretado con un margen suficiente de univocidad), pero un texto "quiere que alguien lo ayude a funcionar " (2003: 76), es decir, que el lector lo actualice ${ }^{4}$. En este sentido, remitimos al utilísimo Diccionario de nuevas formas de lectura y escritura, de Martos y Campos (20I3: 356-359), que registra entradas que desarrollan los conceptos aludidos (s.v. lector ingenuo frente a lector experto.

\section{Leer entre líneas).}

Es obvio que la formación literaria favorece la interacción con la obra, esto es, el pacto de lectura entre texto y autor. El “alumno-lector-activo" participa e interactúa con el texto, de forma que paralelamente desarrolla su formación y educación literarias. Este grado de implicación permite que se desarrollen las competencias lectoras y el método propuesto incide, por tanto, en esta actividad estratégica de re-lectura reflexiva e interpretativa que el alumno completará en el espacio de interacción propuesto en el aula. El discente infiere conocimientos que comunica en un ambiente desinhibido y, paralelamente, desarrolla su formación como lector competente.

\subsection{Integración curricular}

La formación de personas competentes comunicativamente parte de la consideración -tal y como apuntó el padre de la lingüística moderna- de que "el lenguaje es un hecho social” (Saussure, I973: 34). Según López y Encabo (200I: 54), el lenguaje es el "círculo semiótico que sin cesar produce y renueva los significados de los mensajes complejos”, el poder generador de la realidad del lenguaje radica en la conversación que se

\footnotetext{
${ }^{4}$ Según Umberto Eco: "Para organizar su estrategia textual, un autor debe referirse a una serie de competencias (expresión más amplia que "conocimiento de los códigos") capaces de dar contenido a las expresiones que utiliza. Debe suponer que el conjunto de competencias a que se refiere es el mismo al que se refiere su lector. Por consiguiente, deberá prever un Lector Modelo capaz de cooperar en la actualización textual de la manera prevista por él y de moverse interpretativamente, igual que él se ha movido generativamente" (2003: 8o). No consideramos preciso desarrollar los pasos cooperativos ( $c f r$.) para interpretar un texto, esto es, diccionario básico, reglas de correferencia, selecciones contextuales y circunstanciales, hipercodificación, retórica y estilística, inferencias basadas en cuadros comunes, inferencias basadas en cuadros hipertextuales, e hipercodificación ideológica.
} 
produce entre las personas. Como sabemos, el lenguaje no solo consiste en crear producciones concretas, sino en la posibilidad de obtener otras innumerables (Humboldt, I99I). Así la competencia comunicativa se incluye dentro del concepto de noción de generación infinita y de creatividad del lenguaje. Esta perspectiva nos lleva a entenderla como aquello que la persona hablante necesita saber para comunicar de forma eficaz en contextos culturalmente significantes (López y Encabo, 2OoI: 56). Leer y compartir se plantean como un diálogo abierto, permiten que se asienten conocimientos y que se tengan presentes, asimismo, los contenidos sociales y emocionales que se gestan en estos espacios de intercambio comunicativo.

Exponemos los elementos curriculares que recoge la legislación educativa que competen a nuestra propuesta. Partiendo de la estructura helicoidal del currículum y por evidentes cuestiones de espacio, mostraremos el bloque de contenidos referido a "Educación Literaria” del primer ciclo de ESO correspondiente a las normativas vigentes, esto es, LOE y LOMCE.

El currículo de ESO (ORDEN ECI/222O/2007), según la LOE, distingue los siguientes contenidos:

\section{Bloque 3. Educación literaria.}

PRIMER CURSO DE ESO

- Lectura ${ }^{5}$ de varias obras adecuadas a la edad.

- Lectura comentada y recitado de poemas, reconociendo los elementos básicos del ritmo. la versificación y las figuras semánticas más relevantes.

- Lectura comentada de relatos breves, incluyendo mitos y leyendas de diferentes culturas, reconociendo los elementos del relato literario y su funcionalidad.

- Lectura comentada y dramatizada de obras teatrales breves, o de fragmentos, reconociendo los aspectos formales del texto teatral.

- Diferenciación de los grandes géneros literarios, reconociéndolos en las lecturas efectuadas y comentadas.

- Composición de textos de intención literaria utilizando algunos de los aprendizajes adquiridos en las lecturas comentadas.

- Utilización dirigida de la biblioteca del centro y de bibliotecas virtuales.

- Desarrollo de la autonomía lectora y aprecio por la literatura como fuente de placer y de conocimiento del mundo.

${ }^{5}$ Destacamos en negrita los contenidos (conceptuales, procedimentales y actitudinales) así como los aspectos de evaluación que indicen directamente en la formación literaria. 


\section{SEGUNDO CURSO DE ESO}

- Lectura de varias obras adecuadas a la edad.

- Lectura comentada y recitado de poemas, prestando atención al valor simbólico del lenguaje poético, al sentido de los recursos retóricos más importantes, reconociendo los procedimientos de la versificación y valorando la función de todos estos elementos en el poema.

- Lectura comentada de relatos, comparando y contrastando temas y elementos de la historia. formas de inicio, desarrollo cronológico, desenlaces, etc.

- Lectura comentada y dramatizada de fragmentos de obras teatrales, reconociendo algunos subgéneros y prestando atención a la estructura y componentes del texto teatral.

- Diferenciación de los principales subgéneros literarios a través de las lecturas comentadas.

- Composición de textos de intención literaria utilizando algunos de los aprendizajes adquiridos en las lecturas comentadas.

- Utilización progresivamente autónoma de la biblioteca del centro y de bibliotecas virtuales.

- Desarrollo de la autonomía lectora y aprecio por la literatura como fuente de placer y de conocimiento de otros mundos y culturas.

El currículo de ESO (Real Decreto IIO5/20I4) correspondiente a la LOMCE distingue los siguientes contenidos y criterios de evaluación (incluimos estos por considerarlos necesarios para mostrar los contenidos de forma explícita):

\section{PRIMER CICLO DE ESO}

\section{Contenidos}

Bloque 4. Educación literaria

Plan lector.

- Lectura libre de obras de la literatura española y universal y de la literatura juvenil como fuente de placer, de enriquecimiento personal y de conocimiento del mundo para lograr el desarrollo de sus propios gustos e intereses literarios y su autonomía lectora.

- Introducción a la literatura a través de los textos.

- Aproximación a los géneros literarios y a las obras más representativas de la literatura española de la Edad Media al Siglo de Oro a través de la lectura y explicación de fragmentos significativos y, en su caso, textos completos.

\section{Creación.}

- Redacción de textos de intención literaria a partir de la lectura de textos utilizando las convenciones formales del género y con intención lúdica y creativa. 
- Consulta y utilización de fuentes y recursos variados de información para la realización de trabajos.

\section{Criterios de evaluación}

I. Leer obras de la literatura española y universal de todos los tiempos y de la literatura juvenil, cercanas a los propios gustos y aficiones, mostrando interés por la lectura.

2. Favorecer la lectura y comprensión obras literarias de la literatura española y universal de todos los tiempos y de la literatura juvenil, cercanas a los propios gustos y aficiones, contribuyendo a la formación de la personalidad literaria.

3. Promover la reflexión sobre la conexión entre la literatura y el resto de las artes, música, pintura, cine, etc., como expresión del sentimiento humano, analizando e interrelacionando obras (literarias. musicales. arquitectónicas...), personajes, temas, etc. de todas las épocas.

4. Fomentar el gusto y el hábito por la lectura en todas sus vertientes, como fuente de acceso al conocimiento y como instrumento de ocio y diversión que permite explorar mundos diferentes a los nuestros, reales o imaginarios.

5. Comprender textos literarios representativos de la literatura de la Edad Media al Siglo de Oro reconociendo la intención del autor, relacionando su contenido y su forma con los contextos socioculturales y literarios de la época, identificando el tema, reconociendo la evolución de algunos tópicos y formas literarias y expresando esa relación con juicios personales razonados.

6. Redactar textos personales de intención literaria siguiendo las convenciones del género, con intención lúdica y creativa.

7. Consultar y citar adecuadamente fuentes de información variadas, para realizar un trabajo académico en soporte papel o digital sobre un tema del currículo de literatura, adoptando un punto de vista crítico y personal y utilizando las tecnologías de la información.

A partir de la lectura de textos adecuadamente seleccionados -no solo por edades sino también por centros de interés y relaciones curriculares temáticas- se fomenta el uso reflexivo de la lectura mediante la oralidad. El eje de acción metodológica parte de la dinamización de la lengua oral a través de la reflexión literaria. Este aprendizaje, cuyas destrezas orales se utilizan en cualquier situación, se integra en un ambiente de interpretación dialógica y ofrece al alumno la posibilidad de practicar sus habilidades orales en un contexto de interpretación y comprensión textuales. Como sabemos, la enseñanza de la lengua oral en las aulas no suele abordarse de forma explícita, nuestro sistema se apoya principalmente en la lengua escrita (por tradición y quizá porque el docente considera que resulta más concreta la evaluación de estas destrezas, aspecto que no responde a la realidad). La función tradicional de la escuela ha consistido en enseñar a leer y a escribir (Cassany, 2002: 134) y la habilidad de la expresión oral ha sido siempre la gran olvidada 
en las clases. Hoy la escuela continúa confiando en la permanencia de la letra escrita (ya lo dijo el emperador Tito en su famoso discurso: Verba volant, scripta manent). La lengua oral es de difícil recuerdo, no favorece la reflexión como la escrita, y es "complicada" su corrección (Pérez Fernández, 2009: 298). En este sentido, no podemos dejar de mencionar a autores como Mendoza Fillola (2003: 279) o Quiles (2006: $3^{\mathrm{I}-34}$ ) quienes ofrecen interesantes y utilísimos recursos relacionados con la lengua oral y su evaluación. Nuestra vida exige un nivel de comunicación tanto oral como escrito; una persona que no sepa expresarse de forma coherente, clara y correcta limita su proyección personal. Al estimular las destrezas orales en un contexto de interpretación literaria, estamos fomentando diversas competencias que pueden aplicarse, por ejemplo, en la redacción de un texto planteado como escritura creativa.

\section{Método de cooperación interpretativa}

\section{I. Posibilidades lectoras}

Habitualmente se diferencia en las aulas la lectura obligatoria (abordada mediante fichas, resúmenes, cuestionarios, creación de murales, fotonovela, talleres de escritura creativa, presentaciones en power point, blogs, trabajos con kahoot, cómic, diario de lectura, versión musical, trabajo de investigación, dramatización...) frente a la lectura voluntaria (apoyada en la entrevista personal, el libro fórum, el club de lectura...). En nuestro caso partimos de una lectura conjunta que comienza a realizarse en el aula (se recomienda que la obra seleccionada se haya realizado a partir del conocimiento que tiene el profesor de los alumnos y que no forme parte de las programadas para la asignatura pues se trata de un trabajo extra que se va a abordar como estímulo literario). El objeto es crear conciencia en el alumno de que en las clases se establece un tiempo y un espacio de lectura que fomenta el desarrollo personal y que permite compartir opiniones, así como valorar la importancia de abordar actividades compartidas derivadas de la lectura inicial. Estas prácticas se plantean de forma voluntaria; si bien es cierto, que al final participan todos porque se produce un trabajo colaborativo que anima al grupo.

Este "Método de cooperación interpretativa" integra y otorga especial importancia a la oralidad con el fin de conseguir un lector competente, que interactúe y coopere con el texto y que aplique las estrategias necesarias para la comprensión y recreación literarias. El profesor Galera (2003: 383-384) pone de relieve la importancia de enseñar a leer para aprender y considera que las estrategias lectoras se deben poner al servicio de objetivos de aprendizaje de forma que se potencie la funcionalidad de la lectura mediante un aprendizaje significativo. Los alumnos ante un texto -considera este autor- deben comprender los propósitos de la lectura, aportar a la misma sus conocimientos previos, intereses y motivaciones, diferenciar la información relevante de la menos importante, comprobar el proceso comprensivo mediante recapitulación, revisión e interrogación, elaborar inferencias de diversos tipos (interpretaciones, hipótesis, conclusiones...). 


\section{2. Fomento de la competencia lectora}

La literatura es un discurso necesario que ejerce su influencia en la construcción del sujeto, y se consigue mediante la práctica de la competencia comunicativa. La competencia literaria debe ejecutarla el lector para activar aquellas virtualidades significativas que los textos aportan como situación discursiva específica para el desarrollo de la competencia comunicativa en general; es el conjunto de conocimientos y habilidades que permiten no solo disfrutar de los textos literarios, sino también de la posibilidad de construir significados cada vez más complejos sobre los textos leídos e incluso desarrollar la capacidad para concebir el fenómeno literario como producto histórico, cultural, lingǘstico y estético.

El proceso comunicativo complejo que conforma el trabajo de desarrollo de la competencia lectora es uno de los objetivos del método propuesto, según hemos indicado, y en él intervienen diferentes aspectos: el fundamental papel del mediador; la competencia lectora, que posibilita la comprensión primaria y básica del texto literario; el texto mismo, que genera pautas de lectura para establecer relaciones interactivas con el lector que ha de actualizar su existencia; la figura activa y creadora del lector, como sujeto que actualiza el texto interpretándolo y valorándolo; y el intertexto del lector, que permite producir el conjunto de saberes y estrategias lingüístico-culturales para posibilitar el diálogo con los significados y las voces del texto con las de otros textos anteriores.

Nos podemos preguntar cómo se adquiere la competencia literaria. En primer lugar, se concibe como competencia lectora y se asienta en el aprendizaje significativo y en las teorías literarias que inciden en el protagonismo del sujeto como dueño del proceso enunciativo. Una de las claves, tal y como se aprecia en el "Método de colaboración interpretativa”, consiste en sustituir la información literaria por la educación literaria (comprensión lectora, adquisición de hábitos de lectura, capacidad para el análisis y la interpretación, disposición afectiva para disfrutar de las obras literarias y escritura de textos producidos con intención literaria). El alumno es lector competente cuando se siente reconocido en el texto que lee y cuando es capaz de entrar en las reglas del juego a las que le invita el pacto enunciativo según el cual los significados son el resultado de una negociación entre la triple mediación que se produce entre autor, lector y texto. El docente incide en las estrategias, en las operaciones cognitivas, en las actitudes afectivas positivas y en las reflexiones metalingüísticas, frente a los contenidos conceptuales propios del enfoque historicista de la literatura (Núñez y Campos, 2005; Núñez, 2OI4).

La actividad de leer es una operación eminentemente activa que requiere, a la vez que desarrolla, la capacidad de comprensión y de expresión, de interiorización y de comunicación del ser humano. Se plantea la lectura como acto recreativo que le proporciona al lector el placer por lo leído, le ofrece instrumentos para crear o reconstruir un texto y para desarrollar otras capacidades. Los libros acompañan, divierten, estimulan la actividad intelectual, despiertan el gusto por el lenguaje porque constituyen un "enriquecimiento vital". 
La técnica de la recreación literaria produce en el lector un verdadero encuentro con lo leído, dejando un gran espacio para la emoción e interpretación, a la vez que le permite desarrollar sus capacidades de habla, conversación y escucha. Esta estrategia parte de la realidad contextual de los alumnos prelectores, responde a sus intereses y gustos, esto es, se tienen en cuenta los presupuestos de la psicoliteratura -los temas literarios adecuados a estas edades se caracterizan por las aventuras, la intriga, el misterio, el riesgo, la vida real y el mundo afectivo y sentimental-. Se superan así los modelos estructuralistas/nocionales, tan arraigados en contextos docentes, y se concede valor a la lengua como fenómeno social y medio de comunicación para transmitir los saberes relacionados con la lectura. El alumno contextualiza en ámbito literario la expresión oral puesto que reflexiona e interpreta de forma compartida una obra. Esta fase requiere unas estrategias que el mediador le va proporcionando y le guía en su proceso de aprendizaje para que él mismo construya el conocimiento necesario que le permitirá alcanzar los objetivos.

\section{3·3. Desarrollo del método}

La realización de pruebas escritas como actividades de comprensión lectora tras la lectura de un texto es la práctica habitual en las clases de Educación Secundaria. Pues bien, hay que tener en cuenta que estos instrumentos junto con otros que potencian las destrezas comunicativas en contextos compartidos ofrecerán alternativas más completas y estimulantes. Los discentes que se preparan para ser profesores deben conocer estas posibilidades puesto que ellos tomarán el relevo en las aulas (López y Martínez, 2OI2: 28). Ante la pregunta formulada a estos jóvenes en preparación -que cursan el Máster de Formación del Profesorado en Educación Secundaria- sobre su experiencia como alumnos que fueron de ese nivel educativo, la respuesta es unánime: exámenes de control y fichas de lectura. Reconocen que se acostumbraron a estas prácticas escritas y no compartidas, carentes del necesario intercambio oral que cercenaba la reflexión conjunta y en las que no se estimulaba la imaginación ni la sensibilidad hacia el aprecio por los valores estéticos y literarios.

Procedemos a explicar las fases de aplicación del método. El profesor ya conoce a sus alumnos (habilidades, diversidad curricular, temas de interés y también valora la necesidad de abordar determinados temas a partir de las lecturas, bien sean principalmente disciplinares o basados en la educación en valores como ejes transversales), de esta forma, la obra seleccionada cumple una función primordial y responde a expectativas docentes que se han suscitado en el aula. Una vez seleccionada, el docente motiva al alumno comentando el interés de la misma y se abre un pequeño espacio de reflexión sobre temas o aspectos relacionados con la obra. Como ya se ha indicado, se comienza la lectura conjunta en el aula, se alternan fragmentos en voz alta con otros de lectura silenciosa, con el fin de activar la lectura comprensiva del texto (es obvio que el procedimiento de lectura puede variar en función de los niveles). Una vez que la lectura se ha realizado de forma completa, se procede al desarrollo de la propuesta de cooperación interpretativa. 
El método se basa en la inferencia, esto es, se formulan preguntas indirectas con el fin de que el alumno interprete los enunciados y responda de forma reflexiva a cuestiones que no se le han planteado hasta el momento de esa manera. Por otro lado, este procedimiento permite el desarrollo de las destrezas orales en un contexto más formal y a partir de unos contenidos concretos; estos dos aspectos resultan novedosos en este doble ejercicio de oralidad e interpretación literaria compartida.

Los alumnos -preferiblemente ubicados en la biblioteca- se sientan en mesas colocadas en forma de $\mathrm{U}$ con el fin de que puedan verse. Las cuestiones planteadas pueden ser respondidas según las características del grupo (pidiendo el turno de palabra, participando consecutivamente, eligiendo el profesor al alumno..., se trata de atender a la diversidad y dinámica observadas). Todas las preguntas deben invitar a expresar juicios particulares y puntos de vista personales que despierten la sensibilidad hacia los mundos que les ofrece la lectura. El alumno ahora percibe que la obra leída tiene un sentido, la comprende y se convierte en lector activo, por ende, lector competente, en un contexto de cooperación en el que la expresión oral permite el desarrollo de las microhabilidades correspondientes. El discente entiende que el objeto de las preguntas es orientar de forma adecuada la reflexión, la comprensión, la interpretación y la valoración. Esta fase -que para ellos resulta improvisada y espontánea- los prepara para afrontar situaciones en las que la comunicación oral junto con la comprensión razonada de los elementos expuestos conforman un binomio necesario para emplear de forma habitual en ámbitos académicos y en la vida cotidiana.

Mostramos las preguntas que puede ir formulando el profesor o mediador. Se comienza por el apartado más intuitivo e interpretativo porque mediante él se genera un conocimiento compartido que estimula la reflexión y anima a la realización de las siguientes actividades. El contenido trabajado (que figura entre paréntesis) se anota por su utilidad como pauta para abordar los diferentes elementos que suscita la lectura. La guía se estructura en tres apartados que ofrecen, claro está, absoluta flexibilidad:

\section{ELEMENTOS DE INTERPRETACIÓN}

- ¿Consideras que el título se ajusta al contenido? Justifica la respuesta. ¿Le pondrías otro título al libro?, ¿cuál? (TÍTULO).

- ¿Qué asuntos te parece que están bien explicados? Indica los pensamientos que consideres interesantes. Selecciona un fragmento breve que tenga unidad, que te haya gustado, y ponle un título. Elige tres textos: uno narrativo, otro descriptivo y otro dialogado, y explica cuál te resulta más fácil de leer. Indica algunas voces que no hayas entendido, trata de definirlas en sus contextos e incluye algún sinónimo y antónimo. (ELEMENTOS RESEÑABLES).

- Consideras este libro: extraño, interesante, divertido, instructivo, aburrido, poco original... Destaca algunas ideas del autor que se ponen de manifiesto en 
la lectura. Selecciona un ejemplo en el que se argumente a favor o en contra de una idea. ¿Te ha ayudado a formar una opinión algún asunto tratado en el libro? ¿Consideras el estilo claro, difícil...? ¿Te parece que hay ideas expresadas de forma simple, clara, embrollada...? Puntúa la obra sobre seis y razónalo. (INTERÉS DE LA LECTURA).

- ¿Te imaginabas cómo acabaría libro?, ¿te ha sorprendido?, ¿te ha decepcionado?, ¿lo cambiarías? Justifica si consideras que es coherente con el desarrollo de las acciones. (DESENLACE).

\section{ASPECTOS DE LANARRACIÓN}

- ¿Quién ha escrito el libro?, ¿qué sabes del autor?, ¿te gustaría leer otra novela suya? Este apartado admite dos posibilidades de trabajo previo: la consulta bibliográfica puesto que los alumnos ya han sido informados sobre la misma, o también que el mediador la complete a través del visionado de vídeos relacionados con el escritor, la consulta de la página del autor en internet, etc. (AUTOR).

- ¿Hay alguna palabra o expresión que no hayas entendido? Gran parte de estas dudas han sido resueltas en el aula y otras las ha solucionado el alumno durante el proceso de lectura, si bien es el momento de exponerlas y comentarlas. (VOCABULARIO).

- ¿Pondrías otro título al libro? Resume el contenido de la obra en pocas palabras (tres como mucho). En caso de que no aporten ideas, se puede ofrecer el siguiente listado para que vayan justificando su elección: esperanza, heroísmo, muerte, odio, amor, egoísmo, superación, angustia, familia, revolución, absurdo, amistad, pintura de caracteres, pintura de costumbres, ecología, política, etc. (TEMA).

- ¿Qué sucesos se van narrando poco a poco? Resume los hechos más importantes de la obra, pero sin entrar en detalles. (ARGUMENTO).

- ¿En cuántas partes dividirías el libro?,justifícalo. ¿Qué relación observas entre ellas?, ¿responden a planteamiento, nudo y desenlace, o son diferentes? Es conveniente incluir algún ejemplo para repasar estos conceptos, o facilitar al alumno diversas estructuras de fragmentos seleccionados ad hoc. (ESTRUCTURA).

- ¿Quién cuenta la historia?, ¿cómo la cuenta -punto de vista-?, ¿qué personas gramaticales se utilizan?, ¿predomina el diálogo? Es conveniente hacer un repaso sobre estas cuestiones. (TECCICAS NARRATIVAS). 
- ¿Qué personajes aparecen en la obra?, ¿cuáles juzgas más importantes?, ¿cómo son físicamente?, ¿cómo se comportan? Explica cómo son sus caracteres, sentimientos, uso de la lengua, relaciones entre ellos... ¿A qué medio social pertenecen?, ¿sus nombres dicen algo de su manera de ser?, ¿cambian de forma de pensar a lo largo de la historia? (PERSONAJES).

- ¿Dónde se desarrollan las acciones?, ¿son reales?, ¿qué está pasando en la vida de ese lugar en el momento en que transcurren los hechos? Se puede ejemplificar con fragmentos del libro. (LUGARES).

- ¿En qué época, año, día o coordenada temporal ocurren los hechos?, ¿es un tiempo real o imaginario?, ¿hay alusiones concretas al tiempo? (ÉPOCAS).

- ¿Te has identificado con algún personaje o con alguna situación?, ¿qué es lo que más te ha impresionado o gustado y por qué?, ¿qué has sentido al leer el libro? (SENTIMIENTOS).

- Cada alumno escoge los momentos que más le hayan gustado y los analiza respondiendo a las siguientes cuestiones: qué personajes han participado, qué ha ocurrido, cuál ha sido la causa, dónde han tenido lugar, cómo han terminado, qué opina sobre la solución que ofrece autor, o qué posibilidades de cambio permite la misma. (MOMENTOS).

- Un alumno o el profesor, depende de la dinámica generada en la clase, selecciona un párrafo significativo y lo lee en voz alta. Entre todos explicarán si perciben algo especial en el lenguaje utilizado: registro, sintaxis, léxico, elementos morfológicos, etc. Este apartado puede ser todo lo amplio que permita el nivel del grupo y enlaza con contenidos conceptuales fundamentales para repasar en este motivador contexto y de forma eminentemente funcional. (CONOCIMIENTO DE LA LENGUA).

- ¿Crees que el autor ha transmitido algún mensaje?, ¿con qué finalidad crees que ha escrito la obra?, ¿has aprendido algo tras su lectura? (MENSAJE).

\section{TALLERES CREATIVOS}

Se aportan otras estrategias que resultan complementarias y que pertenecen a talleres de creación que son idóneas para relacionar con otras asignaturas, como son pintura, música, historia, cine... Recordemos que el trabajo interdisciplinario es fundamental en este nivel. 
- Este apartado ofrece recursos que permiten la recreación literaria con múltiples posibilidades. Por ejemplo, se puede llevar a cabo el juego del cambio narrativo, es decir, se le propone al alumno que modifique el principio o el final de la obra y, si es preciso, que explique cualquier cambio realizado (con los personajes, alguna acción anterior, otra época, etc.). Se recomienda partir de ideas aportadas por autores que practiquen los talleres: Austin (I988), Delmiro (2002), Kohan y Ariel (199I), Lardone y Andruetto (2007), Martínez (20I4), Queneau (I996, 2009), Rodari (I983), Rincón y Sánchez-Enciso (1985, I987), etc. (TALLER LITERARIO).

- Se resume la lectura, se estructura, se esquematiza y se crea un cómic que se expondrá en clase en tamaño grande. (CÓMIC).

- Se le pide al alumno que grabe un breve anuncio en el que invite a leer el libro a un amigo (los elementos persuasivos son muy importantes y antes se recomienda repasar el lenguaje de la publicidad). (ANUNCIO).

- Como habitualmente carecen de ilustraciones los libros, nos fijaremos en la que presenta la cubierta, y el alumno explicará si es representativa del contenido. Diseñará, asimismo, una nueva cubierta. (ILUSTRACIONES).

Esta guía se ofrece como una posibilidad más entre todas las que el docente puede crear en función de la obra leída, de los alumnos que conformen el grupo o de los aspectos que desee abordar, por ejemplo. La utilidad de la misma se halla justamente en que le permite practicarla de forma acorde a sus objetivos, es decir, que es absolutamente versátil; queremos con ello dejar constancia de que no se destaca su originalidad sino su dimensión polivalente e integradora.

Como ya hemos reseñado, este método fomenta el aprecio por la literatura, la recreación de mundos novelados, el aprendizaje de modelos estructurales, la participación activa y cooperativa, y el estímulo de la imaginación. Pretende animar a los alumnos a que valoren la lectura a partir de sus propias experiencias mediante una propuesta integradora, que recoge con interés las reflexiones del lector con el fin de que comprenda que a través de la interpretación compartida una obra se enriquece, se dialoga con ella y, por tanto, deja una huella -aprendizaje- indeleble. Se busca, en suma, crear lectores competentes porque el acercamiento comprensivo al mundo de los libros parte de la educación literaria, no de la historia de la literatura.

En cuanto al sistema de calificación, es obvio que admite muchas posibilidades, pero lo más importante es explicar que el objetivo inicial no es la "nota alcanzada". Se entiende que esta actividad puede incardinarse en una programación en la que la evaluación es continua, sumativa y formativa. Lo que deseamos destacar es el importante papel del docente que puede comprobar los progresos y las deficiencias de los alumnos en su 
desarrollo con el fin de modificar conductas y actuaciones durante la propia intervención llevada a cabo en el aula o en el espacio que se haya juzgado conveniente.

\section{Conclusiones}

El método aplicado resulta exitoso no solo porque el alumno mejora su capacidad oral, trabaja en equipo, se muestra respetuoso y colaborativo, e interpreta la obra conjuntamente, sino también porque aprende a valorar la lectura como fuente de conocimiento, como enriquecimiento personal y, sobre todo, como una actividad que no considera impuesta y baldía. La propia flexibilidad del currículo junto con la posibilidad de interrelacionar materias, atender a la diversidad, potenciar las competencias básicas y desarrollar el trabajo colaborativo, entre otros aspectos, hacen que este método resulte muy adecuado para ser aplicado en estos contextos educativos.

En cuanto a la dinámica de grupos, se fomentan habilidades y se forman los estudiantes en un espacio adecuado puesto que se desarrollan sus destrezas comunicativas y su capacidad de reflexión e interpretación. Consecuentemente, se producen cambios fundamentales: los alumnos se convierten en sujetos activos de su propio aprendizaje, y el docente pasa de ser la fuente de saber e instrucción a transformarse en un mediador y propiciador del proceso. De forma paralela, desarrollan la sensibilidad hacia el hecho literario -cualidad imprescindible para estadios posteriores-, y asimismo valoran la importancia del texto y la riqueza de la interpretación lectora. Estas herramientas constituyen inestimables recursos que se aplicarán en cualquier situación puesto que se desarrollan competencias necesarias para su vida, tanto en el ámbito escolar como fuera del mismo. Es más, la interacción llevada a cabo en este clima cooperativo es estimulante y constructiva, desarrolla las destrezas sociales y permite el control metacognitivo del grupo. Finalmente, destacamos que la cooperación interpretativa permite reconstruir conjuntamente una lectura, colaborar en equipo, incardinar elementos curriculares y ofrecer estímulos al alumno en un contexto docente que potencia la educación literaria de forma placentera. 


\section{Referencias bibliográficas}

- Austin, J. (I988). Cómo hacer cosas con las palabras. Barcelona: Paidós.

- Campos Fernández-Fígares, M. (2004). Planeando la fuga. Puertas a la lectura, I7, 46-49.

- Cassany, D. et al. (2002). Enseñar lengua. Barcelona: Graó.

- Delmiro, B. (2002). La escritura creativa en las aulas. En torno a los talleres literarios. Barcelona: Graó.

- Eco, U. (1993). Lector in fábula. La cooperación interpretativa en el texto narrativo. Barcelona: Lumen, $3 \cdot{ }^{\mathrm{a}} \mathrm{ed}$.

- Galera, F. (2003). Las actividades para el desarrollo de las habilidades comunicativas, en Antonio Mendoza Fillola (coord.). Didáctica de la Lengua y la Literatura para Primaria. Madrid: Prentice Hall, 38I-424.

- Gómez de Benito, J. (200o). Paradigmas cognitivos y sociales del aprendizaje, en J. Carrillo; J. L. Gómez de Benito; J. C. González y M. Monescillo. Bases psicopedagógicas para la formación inicial del profesora de Secundaria. Huelva: Hergué Editorial, I7 I-I96.

- Humboldt, W. Von (199I). Escritos sobre el lenguaje. Barcelona: Ediciones Península.

- Kohan, S. A. y Ariel, L. (I99I). Taller de escritura. Madrid: Diseño.

- Lardone, L. y Andruetto, M. T. (2007). La construcción del taller de escritura. Sevilla: Homo Sapiens.

- López, A. y Encabo, E. (2OOI). El desarrollo de habilidades lingüísticas. Una perspectiva crítica. Granada: Grupo Editorial Universitario.

- López, A. y Encabo, E. (20I3). Fundamentos didácticos de la lengua y la literatura. Madrid: Editorial Síntesis.

- López, A. y Jerez, I. (20IO). Lectura. escritura y democracia de la cultura. experiencias con la creación literaria. Álabe, 2, I-I6.

- López, A. y Martínez, A. (2OI2) . Aprendizaje y enseñanza de la Lengua Castellana y Literatura. currículo de ESO. Contextos Educativos, I5, 27-40. 
- Marco común europeo de referencia para las lenguas, aprendizaje, enseñanza, evaluación. Consejo de Europa (200I). Madrid: Ministerio de Educación, Cultura y Deporte, Artes Gráficas Fernández Ciudad, S. L. Obtenido el I5 de diciembre de $20{ }_{5}$ desde http://cvc.cervantes.es/obref/marco

- Martínez, A. (2OII). Integración de competencias curriculares en lengua castellana y literatura. Lenguaje y textos, 33, 73-8I.

- Martínez, A. (2OI4). Innovación metodológica en educación literaria. Aprehender figuras retóricas. Didáctica. Lengua y literatura, 26, 263-283.

- Martos, E. y Campos Fernández-Fígares, M. (Coords.) (20I3). Diccionario de nuevas formas de lectura y escritura. Madrid: Santillana-Red Internacional de Universidades Lectoras.

- Martos, E. y Rösing, T. M. K. (Coords.) (2009). Prácticas de lectura y escritura. Brasil: UPF-Universidades Lectoras.

- Mendoza Fillola, A. (2008). La educación literaria. bases para la formación de la competencia lecto-literaria. Alicante: Biblioteca Virtual Miguel de Cervantes. Obtenido el I5 de diciembre de 2015 desde http://www.cervantesvirtual.com/nd/ark./5985I/bmcfigd 9

- Núñez, G. y Campos Fernández-Fígares, M. (2005). Cómo nos enseñaron a leer. Manuales de literatura en España. 1850-1960. Toledo: Akal.

- Núñez, G. (20I4). Lectura literaria y lecturas del mundo. Almería: Editorial Universidad de Almería-Red Internacional de Universidades Lectoras.

- Queneau, R. (I996). Ejercicios de estilo. Madrid: Cátedra, 6. ${ }^{\mathrm{a}} \mathrm{ed}$.

- Queneau, R. (2009). Ejercicios de estilo. Versión y estudio introductorio de A. Fernández Ferrer. Madrid: Cátedra.

- Quiles, M. C. (2006). La comunicación oral. Propuestas didácticas para la educación primaria. Barcelona: Octaedro.

- Quiles, M. C.; Palmer, I. y Rosal, M. (2015): Hablar, leer y escribir. El descubrimiento de las palabras y la educación lingüistica y literaria. Madrid: Visor Libros.

- Rincón, F. y Sánchez-Enciso, J. (1985). Los talleres literarios. Barcelona: Montesinos.

- Rincón, F. y Sánchez-Enciso, J. (1987). Enseñar Literatura. Barcelona: Laia. 
- Rodari, G. (1983). La gramática de la fantasía. Barcelona: Avance.

- Saussure, F. de (1973). Curso de Lingüistica General. Buenos Aires: Losada.

- Stubbs, M. (1984). Lenguaje y escuela. Análisis sociolingüístico de la enseñanza. Madrid: Cincel-Kapelusz.

\section{Referencias legislativas}

- ORDEN ECI/222O/2007, de I2 de julio, por la que se establece el currículo y se regula la ordenación de la Educación Secundaria Obligatoria (BOE, 2I de julio de 2007).

- Real Decreto iro5/20I4, de 26 de diciembre, por el que se establece el currículo básico de la Educación Secundaria Obligatoria y del Bachillerato (BOE, 3 de enero de 2OI5). 